\title{
PENGARUH LIMA DIMENSI BERITA PADA MEDIA ONLINE KHUSUS GAME TERHADAP BRAND AWARENESS PRODUK NINTENDO 3DS
}

(Studi pada Anggota Grup Facebook Handheld Gamers Indonesia)

Aditya Wibowo, Imansyah Lubis

Universitas Telkom

\begin{abstract}
ABSTRAK
Media online sebagai sarana kebutuhan masyarakat sekarang ini sudah menjadi salah satu faktor dalam meningkatkan kesadaran akan suatu brand khususnya pada video game. Nintendo sebagai salah satu perusahaan game dunia memiliki produk Nintendo 3DS yang dirilis pada tahun 2011. Dari produk tersebut, banyak media online khusus game yang memberitakan perkembangan produk baik fitur maupun software yang mendukung. Perumusan masalah dalam penelitian ini adalah bagaimana tanggapan/ respon audience media berita online khusus game tentang produk Nintendo 3DS pada media online khusus game, seberapa besar awareness audience pada produk Nintendo 3DS dan seberapa besar pengaruh media online khusus game terhadap Brand Awareness Nintendo 3DS. Hasil penelitian menunjukkan bahwa komponen dari berita online yaitu variabel Timeliness, Proximity, Prominence, Consequence, dan Human Interest berpengaruh secara bersama-sama terhadap Brand Awareness sebesar 52,7\% dan sisanya sebesar 47,3\% dipengaruhi oleh variabel-variabel bebas lain yang tidak termasuk dalam penelitian ini.
\end{abstract}

Kata-kata kunci: Berita online, kesadaran merek

\section{EFFECT OF THE FIVE NEWS DIMENSIONS ON ONLINE GAMES MEDIA TOWARDS NINTENDO 3DS BRAND AWARENESS}

\begin{abstract}
Online media has become a necessary in today's society, and become one of the factors in increasing the awareness of a brand especially video game. Nintendo as a one of the biggest game company in the world owns Nintendo 3DS which was released to public in 2011. The product, has many news online media which was report the product specification or software supporting the operating system. Problem formulation for this research is to find out how the reaction/response of the audience of online media specifically for video game, how the audience awareness of Nintendo product and how big the influence of online media specifically for video game to Nintendo 3DS brand awareness. The result of this research shows that components of online news includes timeliness, proximity, prominence, consequence, and human interest variables altogether influenced the brand awareness for $52,7 \%$ and $47,3 \%$ is influenced by other free variables which is not included in this research.
\end{abstract}

Keywords: Online news, brand awareness

Korespondensi: Imansyah Lubis, S.Sos., M.Ds. Universitas Telkom, JL. Telekomunikasi No. 1, Dayeuh Kolot, Bandung, Jawa Barat, 40257, Indonesia.Email: imansyah.lubis@gmail.com, imansyahlubis@telkomuniversity.ac.id 


\section{PENDAHULUAN}

Nintendo adalah sebuah perusahaan multinasional yang bergerak dalam bidang video game. Didirikan pada 23 September 1889 yang awalnya difokuskan pada produksi permainan kartu. Namun semenjak melihat pasar hiburan di Amerika, akhirnya Nintendo berpindah haluan menjadi produsen video game baik hardware maupun software. Tahun 2010 Nintendo mungumumkan akan merilis handheld baru sebagai penerus NDS, dengan kemampuan mampu menampilkan efek 3D tanpa memerlukan kacamata khusus. pada tahun 2011 Nintendo akhirnya merilis Nintendo 3DS diikuti oleh Sony yang juga merilis Play Station Vita, dimana sampai tahun 2013 Nintendo 3DS terjual sampai 29,8 juta unit dan Play Station Vita sebesar 4,49 juta unit. Selain itu IGN sebagai salah satu website video game international membuat urutan pembuat video game terkenal dan ternyata Nintendo menduduki posisi pertama sebagai pembuat video game yang sudah lama bertahan selama tiga decade dan mam$\mathrm{pu}$ memberikan revolusi pada industri video game.

Di Indonesia sudah sejak lama video game masuk sebagai salah satu hiburan, dimana pada awal tahun 2000an terdapat tiga majalah game besar yang sering memberikan informasi dunia game dari seluruh dunia. Namun sekarang ini, majalah video game sudah jarang dikonsumsi oleh masyarakat karena kehadiran internet yang sudah menjadi konsumsi umum dimana siapapun bisa mengakses internet. Merdeka. com melaporkan bahwa sampai tahun 2012, pengguna internet di Indonesia telah mencapai 63 Juta pengguna dan diperkirakan untuk tahun-tahun selanjutnya akan lebih meningkat lagi. Berdasarkan hal tersebut maka penelitian ini berfokus pada pengguna internet yang menggunakan media online khusus game untuk mencari tahu tentang Nintendo 3DS yang merupakan produk dari Nintendo.

Salah satu grup di jejaring sosial Facebook yaitu Handheld Gamers Indonesia dijadikan sebagai objek penelitian. Di Indonesia sambutan untuk Nintendo 3DS cukup baik dimana sampai saat ini banyak gamer yang membuat berbagai grup komunitas untuk membahas produk dari Nintendo ini. Hal ini tidak terlepas dari faktor-faktor seperti industri game mau- pun internet yang mendukung masyarakatnya dalam menyampaikan apa yang diinginkan dari produk sejenis. Fakta tersebut ditambah dengan artikel dari Kotaku yang mengatakan Nintendo 3DS sebagai "The best video game systems are, quite simply, the systems that have the best games in 2013, that's the 3DS"

Hal tersebut di atas menjadi dasar dari penelitian ini, yaitu untuk meneliti seberapa besar pengaruh berita media online terhadap brand awareness produk Nintendo 3DS.

Berdasarkan latar belakang yang telah diuraikan, maka dapat dirumuskan permasalahan yang akan dibahas dalam penelitian ini yaitu bagaimana tanggapan/ respon audience media berita online khusus game mengenai Nintendo 3DS pada media online khusus game?, seberapa besar awareness audience pada produk Nintendo 3DS?, dan seberapa besar pengaruh lima dimensi berita pada media online khusus game terhadap Brand Awareness Nintendo 3DS?

Jurnalistik online merupakan proses dalam menyebarkan berita melalui media internet secara online dan merupakan generasi baru setelah jurnalistik konvensional (jurnalistik media cetak atau surat kabar) dan jurnalistik penyiaran (broadcast journalism-radio atau televisi). (Romli, 2012: 11).

Secara umum terdapat dua jenis penulisan, yaitu fiksi atau nonfiksi. Fiksi bisa disebut sebagai khayalan atau imajinasi penulis seperti cerpen, novel, puisi, dan drama. Untuk nonfiksi, biasanya didasarkan pada sebuah peristiwa yang terjadi (fakta dan data yang valid). Dalam dunia jurnalistik, terdapat berbagai karya penulisan nonfiksi yang terbagi menjadi tiga, yaitu berita (news), artikel (views), dan karangan khas (features).

Berita adalah laporan peristiwa terbaru. Menurut Dominick (2012: 311) ada lima elemen inti nilai berita yang menjadi ciri suatu kejadian layak diberitakan yang sudah disetujui oleh banyak jurnalis yang telah meliput berbagai peristiwa yaitu Timeliness, Proximity, Prominence, Consequence dan Human Interest.

Artikel didefinisikan sebagai sebuah karangan tentang suatu masalah secara lengkap, yang panjangnya tak tentu untuk dimuat di surat kabar, majalah bulletin, dan sebagainya, dengan tujuan untuk menyampaikan gagasan dan fakta guna meyakinkan, mendidik, men- 
awarkan pemecahan untuk suatu masalah, atau menghibur (Romli, 2012: 74).

Feature diartikan sebagai cerita pendek (cerpen) yang kisahnya factual (menceritakan suatu peristiwa yang telah terjadi) (Romli, 2012: 79).

Media online merupakan produk jurnalistik online atau cyber journalisme yang didefinisikan sebagai "pelaporan fakta atau peristiwa yang diproduksi dan didistribusikan melalui internet". Menurut Romli (2012: 30) Media Online disebut juga cybermedia, media internet dan media baru, dapat diartikan sebagai media yang tersaji secara online di situs website internet. Juga bisa disebut sebagai media generasi ketiga setelah media cetak dan media elektronik.

Stewart dan Kowaltzke (2010: 425) menjelaskan bahwa video game adalah sebuah video atau permainan komputer yang terbentuk dari kombinasi antara elemen board game, buku, movie, dan olahraga. Yang disampaikan secara elektronik baik melalui mesin arcade ataupun konsol permainan atau komputer dirumah. Video games biasanya menempatkan sebuah cerita atau misi didalam environment yang disimulasikan secara realistis atau secara fantasy reality.

Brand Awareness adalah kemampuan seseorang yang merupakan calon pembeli (poten- tial buyer) untuk mengenali (recognize) atau menyebutkan kembali (recall) suatu merek merupakan bagian dari suatu kategori produk (Aaker, 1991: 61). Tahapannya adalah Unaware of a brand, Brand Recognition, Brand Recall, dan Top of Mind

Unaware of a brand: Pada tingkatan ini seseorang tidak mengetahui suatu Brand tertentu. Berdasarkan cara pandang konsumen, sebuah merek tidak memiliki ekuitas hingga konsumen menyadari keberadaan merek tersebut. Mencapai kesadaran akan merek adalah tantangan utama merek baru. Mempertahankan tingkat kesadaran merek yang tinggi adalah tugas yang harus dihadapi oleh semua merek

Brand Recognition: Pada tingkatan ini, merupakan tingkatan paling rendah dari awareness seseorang. Kenal akan merek (brand recognition) mencerminkan tingkat kesadaran yang cenderung dangkal. Implikasi dari brand Recognition ini menjadi penting ketika seseorang berada pada suatu point of purchase, seperti seseorang ketika berada di supermarket.

Brand Recall: tahapan ini lebih tinggi dibandingkan pada tahap recognition. Pada tahap ini seseorang diminta untuk menyebutkan nama-nama produk dalam suatu kategori produk tertentu tanpa melalui bantuan seperti pada tahap recognition. Mampu mengingat merek (brand recall) mencerminkan ke-

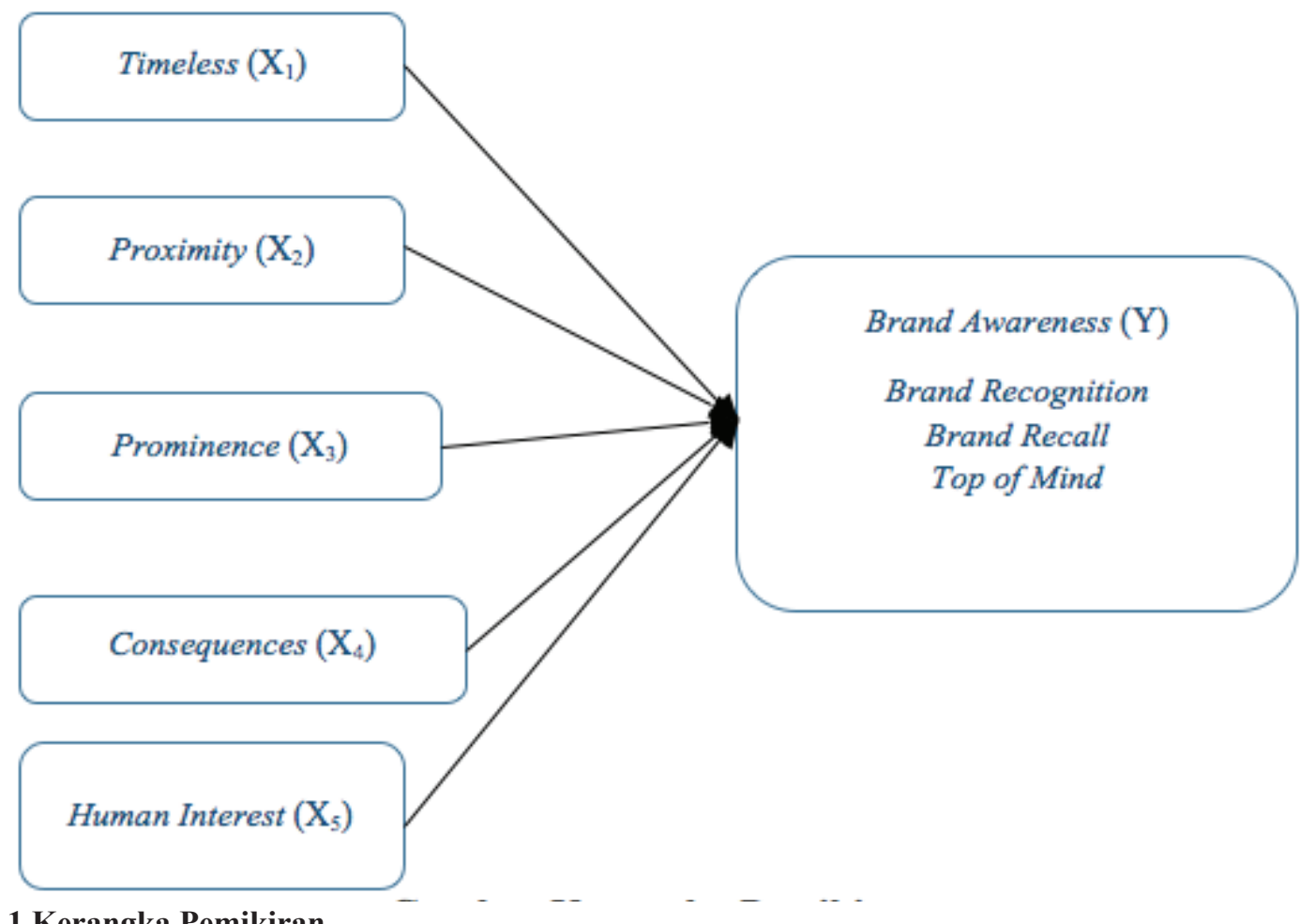

Gambar 1 Kerangka Pemikiran 
sadaran yang lebih dalam. Konsumen dapat mengidentifikasi sebuah merek jika mereka diberi daftar merek-merek atau diberi sedikit petunjuk tentang merek tertentu. Namun, hanya sedikit konsumen yang dapat mengingat sebuah merek dari mereka tanpa bantuan suatu pengingat atau petunjuk. Pemasar tentu menginginkan tingkat kesadaran yang lebih dalam yaitu mampu diingat.

Top of Mind, adalah nama suatu merek atau Brand yang disebutkan pertama kali oleh seseorang, berada pada posisi yang istimewa. Dalam pengertian sederhana, merek tersebut menjadi pimpinan dalam benak konsumen tersebut dibandingkan nama merek-merek lain (Aaker, 1991: 62). Pentingnya komunikasi pemasaran adalah untuk memindahkan merek dari keadaan ketidaksadaran, pengakuan, untuk mengingat, dan akhirnya untuk kesadaran top of mind (TOMA). Puncak ini nama brand awareness ada ketika merek perusahaan anda adalah merek pertama yang konsumen ingat ketika berpikir tentang merek dalam kategori produk tertentu.

Berdasarkan kerangka berpikir yang telah diuraikan diatas maka hipotesis dalam penelitian ini adalah sebagai berikut:

- $\mathrm{H}_{0}$ : Berita online tidak berpengaruh terhadap brand awareness produk Nintendo 3DS.

- $\mathrm{H}_{1}$ : Berita online berpengaruh terhadap brand awareness produk Nintendo 3DS.

- Adanya komponen pada Berita Online membuat penelitian ini mempunyai beberapa sub-hipotesis, yaitu:

- $\mathrm{H}_{0} \mathrm{X}_{1}$ : Timeliness tidak berpengaruh terhadap brand awareness produk Nintendo 3DS.

- $\mathrm{H}_{0} \mathrm{X}_{2}$ : Proximity tidak berpengaruh terhadap brand awareness produk Nintendo 3DS.

- $\mathrm{H}_{0} \mathrm{X}_{3}$ : Prominence tidak berpengaruh terhadap brand awareness produk Nintendo 3DS.

- $\mathrm{H}_{0} \mathrm{X}_{4}$ : Consequence tidak berpengaruh terhadap brand awareness produk Nintendo 3DS.

- $\mathrm{H}_{0} \mathrm{X}_{5}$ : Human Interest tidak berpengaruh terhadap brand awareness produk Nintendo 3DS.
- $\mathrm{H}_{1} \mathrm{X}_{1}$ : Timeliness berpengaruh terhadap brand awareness produk Nintendo 3DS.

- $\mathrm{H}_{1} \mathrm{X}_{2}$ : Proximity berpengaruh terhadap brand awareness produk Nintendo 3DS

- $\mathrm{H}_{1} \mathrm{X}_{3}$ : Prominence berpengaruh terhadap brand awareness produk Nintendo 3DS

- $\mathrm{H}_{1} \mathrm{X}_{4}$ : Consequence berpengaruh terhadap brand awareness produk Nintendo 3DS

- $\mathrm{H}_{1} \mathrm{X}_{5}$ : Human Interest berpengaruh terhadap brand awareness produk Nintendo 3DS

\section{METODE PENELITIAN}

Penelitian ini menggunakan dua jenis penelitian yaitu deskriptif dan kausal. Penelitian deskriptif dilakukan untuk mengetahui dan menjelaskan karakteristik variabel yang diteliti dalam suatu situasi (Sekaran, 2009: 158). Penelitian kausal adalah penelitian yang dilakukan untuk mengidentifikasi hubungan sebab akibat antar variabel (Sarwono dan Martadiredja, 2008: 59).

Variabel independen dalam penelitian ini adalah lima dimensi dari berita online khusus game dan variabel dependennya adalah brand awareness produk Nintendo 3DS. Populasi dalam penelitian ini adalah anggota grup Facebook Handheld Gamer Indonesia dengan menggunakan persamaan slovin dan tingkat signifikansi 5\%, maka diperoleh sampel dalam penelitian ini minimal 276 dan dibulatkan menjadi 280 responden.

Skala yang digunakan dalam penelitian ini adalah skala ordinal. Skala ordinal menunjukkan ada tingkatan atau peringkat berupa kategori-kategori untuk menunjukkan kategori yang satu lebih baik dari anggota lainnya, namun jarak antara masing-masing kategori tidak sama (Mulyatiningsih, 2012: 34). Skala kuesioner yang digunakan adalah skala likert 4 skala. Skala likert digunakan untuk mengukur sikap, pendapat dan persepsi seseorang atau sekelompok orang tentang fenomena sosial (Sugiyono, 2011: 93).

Teknik analisis yang digunakan dalam penelitian ini adalah teknik analisis regresi linier berganda. Hal ini dimaksudkan untuk meneliti pengaruh sub variabel iklan bersambung (video, audio dan kontinuitas) secara simultan maupun parsial terhadap keputusan pembelian. 


\section{HASIL DAN PEMBAHASAN}

Berdasarkan data penelitian yang diperoleh tentang karakteristik responden, diketahui bahwa jumlah responden laki-laki menjadi mayoritas dibanding responden perempuan. Berdasarkan usia, responden yang dominan adalah kelompok usia 17-25 tahun dimana sebagian besar mereka berprofesi sebagai pelajar/mahasiswa. Selain itu, analisis karakteristik responden juga dilakukan dengan analisis crosstab sebagai berikut:

Tabel di atas menunjukkan bahwa dari 280 responden dengan jenis kelamin laki-laki dalam kategori usia kurang dari 17 tahun dapat dilihat bahwa seluruh responden yang berjumlah 15 responden berprofesi sebagai pelajar/ mahasiswa, responden dengan rentan usia 1725 tahun menunjukkan bahwa 107 responden berprofesi sebagai pelajar/mahasiswa, 3 responden berprofesi sebagai pegawai negeri/ swasta. Responden dengan rentang usia 26-35 tahun menunjukkan bahwa 44 responden berprofesi sebagai pegawai negeri/swasta, 13 responden berprofesi sebagai wiraswasta dan 7 responden berprofesi lainnya, serta responden dengan usia lebih dari 35 tahun menunjukkan bahwa 3 responden berprofesi sebagai pegawai negeri/swasta, 2 responden berprofesi se- bagai wiraswasta dan 2 responden berprofesi lainnya.

Berita online khusus game terdiri dari 5 dimensi yaitu Timeliness, Proximity, Prominence, Consequence, dan Human Interest menurut tanggapan responden rata-rata berada dalam kategori baik. Pemberitaan mengenai Nintendo 3DS menurut tanggapan audience media berita online rata-rata berada dalam kategori baik. Dalam hal ini media berita online khusus game selalu menyajikan berita terbaru dan cepat mengenai produk Nintendo 3DS, sehingga audience media berita online khusus game selalu mendapatkan berita terkini secara cepat mengenai produk Nintendo 3DS. Dari segi proximity juga sudah baik, dalam hal ini audience media berita online khusus game pernah memiliki pengalaman mengenai produk Nintendo 3DS. Selain itu berita-berita yang disampaikan oleh media berita online khusus game mengenai event Nintendo 3DS juga pernah terjadi di sekitar audience media berita online khusus game. Sehingga audience media berita online khusus game memiliki kedekatan geografis dan psikologis dengan berita Nintendo 3DS yang disampaikan. Dari segi prominence juga sudah baik terutama dalam pengetahuan audience media berita online khusus game mengenai produk Nintendo

Tabel 1 Analisis Crosstab Karakteristik Responden

\begin{tabular}{|c|c|c|c|c|c|c|}
\hline \multirow[b]{2}{*}{$\begin{array}{l}\text { Jenis } \\
\text { Kelamin }\end{array}$} & \multirow[b]{2}{*}{ Usia } & \multicolumn{4}{|c|}{ Pekerjaan } & \multirow[b]{2}{*}{ Total } \\
\hline & & $\begin{array}{c}\text { Pelajar/ } \\
\text { Mahasiswa }\end{array}$ & $\begin{array}{c}\text { Pegawai Negeri/ } \\
\text { Swasta }\end{array}$ & Wiraswasta & Lainnya & \\
\hline \multirow{4}{*}{ Laki-Laki } & $<17$ tahun & 15 & 0 & 0 & 0 & 15 \\
\hline & $\begin{array}{l}17-25 \\
\text { tahun }\end{array}$ & 107 & 40 & 9 & 13 & 169 \\
\hline & $\begin{array}{l}25-35 \\
\text { tahun }\end{array}$ & 3 & 44 & 13 & 7 & 67 \\
\hline & $>35$ tahun & 0 & 3 & 2 & 2 & 7 \\
\hline \multicolumn{2}{|c|}{ Total } & 125 & 87 & 24 & 22 & 258 \\
\hline \multirow[t]{4}{*}{ Perempuan } & $<17$ tahun & 1 & 0 & 0 & 0 & 1 \\
\hline & $\begin{array}{l}17-25 \\
\text { tahun }\end{array}$ & 11 & 0 & 0 & 0 & 11 \\
\hline & $\begin{array}{l}25-35 \\
\text { tahun }\end{array}$ & 0 & 7 & 2 & 0 & 9 \\
\hline & $>35$ tahun & 0 & 1 & 0 & 0 & 1 \\
\hline \multicolumn{2}{|c|}{ Total } & 12 & 8 & 2 & 0 & 22 \\
\hline
\end{tabular}


3DS dan rata-rata audience media berita online khusus game juga mengikuti pemberitaan mengenai game tertentu dan fitur-fitur yang berhubungan dengan Nintendo 3DS di media online khusus game. Media berita online khusus game juga memberitakan tentang artis terkenal yang menggunakan produk Nintendo 3DS. Lalu pada segi consequence tanggapan audience media berita online berada dalam kategori baik, dalam hal ini artinya sebuah nilai berita dibangun dari pemberitaan mengenai produk Nintendo 3DS di media berita online khusus game yang memiliki dampak besar pada gamer maupun industri game. Dan audience juga mencari tahu berita mengenai penjualan Nintendo 3DS yang ada di seluruh dunia untuk mengetahui hasil penjualan Nintendo 3DS dibanding produk lainnya. Selain itu dalam segi human interest berada pada kategori baik, dalam hal ini audience media berita online khusus game tertarik pada berita mengenai Nintendo 3DS secara mendalam sehingga audience media berita online khusus game cenderung terbawa emosi (positif/negatif) ketika membaca mengenai produk Nintendo 3DS. Awareness audience media berita online khusus game mengenai produk Nintendo 3DS secara deskriptif sudah baik. Audience media berita online khusus game mengetahui baru dan cepat nya tentang informasi Nintendo 3DS, mengetahui adanya event mengenai Nintendo 3DS di sekitarnya, mengetahui game, fitur maupun artis yang berhubungan dengan Nintendo 3DS, mengetahui dampak Nintendo 3DS pada gamer dan industri game dan memiliki penilaian positif maupun negatif mengenai produk Nintendo 3DS.

Adapun hasil pengujian hipotesis pada penelitian ini menunjukkan bahwa Berita online terdiri dari lima komponen yang membentuk berita yaitu variabel Timeliness $\left(\mathrm{X}_{1}\right)$ dengan nilai Signifikansi $0,000<0,05$ dan nilai $t_{\text {hitung }}$ $(4,465)>t_{\text {tabel }}(1,96)$, Proximity $\left(\mathrm{X}_{2}\right)$ dengan nilai Signifikansi $0,611>0,05$ nilai $t_{\text {hitung }}$ $(-0,510)<\mathrm{t}_{\text {tabel }}(1,96)$, Prominence $\left(\mathrm{X}_{3}\right)$ dengan nilai Signifikansi $0,001<0,05$ nilai $t_{\text {hitung }}$ $(3,445)>\mathrm{t}_{\text {tabel }}(1,96)$, Consequence $\left(\mathrm{X}_{4}\right)$ dengan nilai Signifikansi $0,006<0,05$ nilai $t_{\text {hitung }}$ $(2,770)>t_{\text {tabel }}(1,96)$, dan Human Interest $\left(\mathrm{X}_{5}\right)$ dengan nilai Signifikansi $0,000<0,05$ nilai $\mathrm{t}_{\text {hitung }}(6,816)>\mathrm{t}_{\text {tabel }}(1,96)$. Hal ini menunjukkan bahwa secara parsial variabel berita on- line yang terdiri dari Timeliness $\left(\mathrm{X}_{1}\right)$, Proximity $\left(\mathrm{X}_{2}\right)$, Prominence $\left(\mathrm{X}_{3}\right)$, Consequence $\left(\mathrm{X}_{4}\right)$, dan Human Interest $\left(\mathrm{X}_{5}\right)$ berpengaruh signifikan terhadap variabel terikat yaitu Brand Awareness (Y).

Dari perhitungan SPSS, diperoleh persamaan regresi linier berganda sebagai berikut:

$$
\begin{aligned}
\mathrm{Y}=8,033 & +0,738 \mathrm{X}_{1}+(-, 0,68) \mathrm{X}_{2}+0,454 \mathrm{X}_{3} \\
& +0,336 \mathrm{X}_{4}+1,169 \mathrm{X}_{5}
\end{aligned}
$$

Dari persamaan regresi linier berganda di atas, dapat ditarik kesimpulan bahwa setiap kenaikan satu satuan variabel dimensi berita (timeliness, proximity, prominence, consequence, dan human interest) maka nilai brand awareness akan mengalami peningkatan sebesar nilai koefisien regresi dari masing-masing dimensi berita online dengan asumsi nilai dimensi berita online lainnya bernilai konstan.

Hasil perhitungan SPSS dalam Tabel 4.12 dapat diketahui diperoleh angka $\mathrm{R}^{2}$ (R Square) sebesar 0,527. Hal ini menunjukkan bahwa komponen dari berita online $(\mathrm{X})$ yaitu variabel Timeliness $\left(\mathrm{X}_{1}\right)$, Proximity $\left(\mathrm{X}_{2}\right)$, Prominence $\left(\mathrm{X}_{3}\right)$, Consequence $\left(\mathrm{X}_{4}\right)$, dan Human Interest $\left(\mathrm{X}_{5}\right)$ berpengaruh secara bersama-sama terhadap Brand Awareness (Y) sebesar 52,7\% dan sisanya sebesar $47,3 \%$ dipengaruhi oleh variabel-variabel bebas lain yang tidak termasuk dalam penelitian ini.

\section{SIMPULAN}

Dari rumusan masalah penelitian yang diajukan dan analisis data yang telah dilakukan serta pembahasan yang telah dikemukakan pada sebelumnya, maka dapat ditarik kesimpulan sebagai berikut:

Berita online khusus game terdiri dari 5 dimensi yaitu Timeliness, Proximity, Prominence, Consequence, dan Human Interest menurut tanggapan responden rata-rata berada dalam kategori baik. Pemberitaan mengenai Nintendo 3DS menurut tanggapan audience media berita online rata-rata berada dalam kategori baik. Dalam hal ini media berita online khusus game selalu menyajikan berita terbaru dan cepat mengenai produk Nintendo 3DS, sehingga audience media berita online khusus game selalu mendapatkan berita terkini secara cepat mengenai produk Nintendo 3DS. Dari segi proximity juga sudah baik, dalam hal ini audience media berita online khusus 
game pernah memiliki pengalaman mengenai produk Nintendo 3DS. Selain itu berita-berita yang disampaikan oleh media berita online khusus game mengenai event Nintendo 3DS juga pernah terjadi di sekitar audience media berita online khusus game. Sehingga audience media berita online khusus game memiliki kedekatan geografis dan psikologis dengan berita Nintendo 3DS yang disampaikan. Dari segi prominence juga sudah baik terutama dalam pengetahuan audience media berita online khusus game mengenai produk Nintendo 3DS dan rata-rata audience media berita online khusus game juga mengikuti pemberitaan mengenai game tertentu dan fitur-fitur yang berhubungan dengan Nintendo 3DS di media online khusus game. Lalu pada segi consequence tanggapan audience media berita online berada dalam kategori baik, dalam hal ini artinya sebuah nilai berita dibangun dari pemberitaan mengenai produk Nintendo 3DS di media berita online khusus game yang memiliki pengaruh pada gamer maupun industri game. Dan audience juga mencari tahu berita mengenai penjualan Nintendo 3DS yang ada di seluruh dunia untuk mengetahui hasil penjualan Nintendo 3DS dibanding produk lainnya. Selain itu dalam segi human interest berada pada kategori baik, dalam hal ini audience media berita online khusus game tertarik pada berita mengenai Nintendo 3DS secara mendalam sehingga audience media berita online khusus game cenderung terbawa emosi (positif/negatif) ketika membaca mengenai produk Nintendo 3DS.

Awareness audience media berita online khusus game mengenai produk Nintendo 3DS secara deskriptif sudah baik. Audience media berita online khusus game mengetahui baru dan cepat nya tentang informasi Nintendo 3DS, mengetahui adanya event mengenai Nintendo 3DS di sekitarnya, mengetahui game, fitur maupun artis yang berhubungan dengan Nintendo 3DS, mengetahui dampak Nintendo 3DS pada gamer dan industri game dan memiliki penilaian positif maupun negatif mengenai produk Nintendo 3DS.

Nilai koefisiensi determinasi atau $\mathrm{R}^{2}(\mathrm{R}$ Square) sebesar 0,527. Hal ini menunjukkan bahwa komponen dari berita online $(\mathrm{X})$ yaitu variabel Timeliness $\left(\mathrm{X}_{1}\right)$, Proximity $\left(\mathrm{X}_{2}\right)$, Prominence $\left(\mathrm{X}_{3}\right)$, Consequence $\left(\mathrm{X}_{4}\right)$, dan Human
Interest $\left(\mathrm{X}_{5}\right)$ berpengaruh secara bersama-sama terhadap Brand Awareness (Y) sebesar $52,7 \%$ dan sisanya sebesar $47,3 \%$ dipengaruhi oleh variabel-variabel bebas lain yang tidak termasuk dalam penelitian ini.

Berdasarkan hasil penelitian dan pembahasan yang telah dilakukan, maka akan disajikan beberapa saran yang dimaksudkan sebagai masukan bagi pihak perusahaan maupun bagi penelitian selanjutnya.

Saran bagi Nintendo Co., Ltd. adalah hendaknya membangun komunikasi yang lebih efektif lagi dengan media online. Seperti yang diketahui, Nintendo adalah perusahaan game yang sudah berdiri sejak lama namun masih bertahan sampai saat ini. Untuk itu supaya produknya makin dikenal, perlu dilakukan peningkatan dalam Timeliness, Proximity, Prominence, Consequence dan Human Interest. yaitu (1) Selalu memberikan berita dengan cepat tentang Nintendo 3DS maupun produk lainnya agar para audience lebih mengenal dan mengetahui perkembangan Nintendo beserta produknya. (2) Lebih banyak memberikan promosi tentang produknya dengan mengajak figur-figur terkenal seperti artis-artis Hollywood agar orang awam pun bisa mengenal produk-produk dari Nintendo. (3) Nintendo lebih sering lagi dalam memberikan berita penjualan produk-produknya terutama Nintendo 3DS agar menjadi sesuatu yang bisa berdampak pada audience dimana audience bisa membandingkan dengan produk dari perusahaan lain. (4) Lebih sering memberikan berita yang bisa mempengaruhi emosi para audience dalam menanggapi hal mengenai Nintendo dan produknya

Hal-hal ini dilakukan agar Nintendo makin dikenal lagi oleh masyarakat khususnya masyarakat Indonesia.

Saran bagi penelitian selanjutnya, terutama bagi yang berminat untuk meneliti dengan studi kasus pada pengaruh berita online terhadap suatu brand, karena pada penelitian ini hanya menggunakan lima variabel yang menjadi komponen dalam membentuk berita dengan jumlah anggota objek 1634 anggota dari grup Nintendo 3DS. Diharapkan untuk penelitian selanjutnya bisa menggunakan objek dengan data terbaru dari grup Nintendo 3DS Streetpass Indonesia dan mengembangkan lagi pada variabel bebas yang lain di luar model peneli- 
tian. Hal ini dikarenakan bahwa dalam penelitian ini yang terdiri dari variabel bebas (timeliness, proximity, prominence, consequence, dan human interest) hanya berpengaruh sebesar $52,7 \%$ terhadap variabel terikat (brand awareness) dan sisanya $47,3 \%$ dapat dijelaskan oleh variabel lain. Dengan demikin disarankan untuk peneliti selanjutnya untukmencoba meneliti dengan menggunakan variabel lain seperti efek komunitas (yang menjadi tempat pengambilan sampel adalah suatu komunitas) atau variabel lainnya yang dapat meningkatkan brand awareness suatu produk.

\section{DAFTAR PUSTAKA}

Aaker, D. A,. (1991). Managing brand equity. New York, NY: The Free Press.
Dominick, J. R. (2011). The dynamics of mass communication $12^{\text {th }}$ edition. New York:

McGraw-Hill.

Mulyatiningsih, E. (2012). Metodologi Penelitian terapan bidang pendidikan. Bandung: Alfabeta

Romli, A. S. M. (2012). Jurnalistik online. Bandung: Nuansa

Sarwono, J. \& Martadiredja, T. (2008). Riset bisnis untuk pengambilan keputusan. Yogyakarta: Andi Offset

Sugiyono. (2011). Metodologi penelitian kuantitatif, kualitatif, dan $R \& D$. Bandung: Alfabeta.

Suliyanto. (2011). Ekonometrika terapan: teori \& aplikasi dengan SPSS. Yogyakarta: Andi Offset. 